\title{
How to do it: send an article to The Ceylon Medical Journal
}

The Ceylon Medical Journal (CMJ) is published quarterly (end of March, June, September and December) by the Sri Lanka Medical Association. Material received for publication in the $C M J$ must not be submitted for publication elsewhere without the editors' permission (see below under Previous Publication and under Cover Letter).

\section{Contents}

The $C M J$ publishes original papers and commentaries which have relevance to medicine and allied sciences.

\section{Leading articles}

Leading articles are solicited by the editors, and are expert opinions on current topics or commentaries on other papers published in the $C M J$. They do not usually exceed 1500 words or have more than 20 references. Tables and illustrations are usually not included in leading articles.

Papers

Original work concerning the causes, mechanisms, diagnosis, management and prevention of disease belong in this category. So do articles on health systems research, health economics and management, and medical ethics. They should have less than 2000 words, 5 tables / illustrations.

\section{Brief reports}

This category includes preliminary reports, new patient management methods, and reports of new techniques and devices. They should be limited to 1000 words, 3 tables/illustrations and 10 references, and can include a summary of less than 100 words.

\section{Case reports}

Acceptance of case reports is based strictly on originality and whether there is an important clinical lesson to be learnt from the report. It should not contain more than 750 words, one table / illustration and 5 references. Authorship should be limited to five.

Case reports may be accepted as contributions to the picture-story series (not more than 300 words of text, 3 references and 2 clear black and white or colour photographs).

\section{Perspectives and points of view}

The $C M J$ also welcomes essays expressing opinions, presenting hypotheses, broaching controversial issues, clarifying recent advances in the basic sciences, and essays pertaining to medical education, history of medicine, health politics and patients' rights. They should not have more than 750 words and 10 references.

\section{Miscellany}

The $C M J$ will also consider for publication letters (less than 400 words, 3 authors, and 5 references).

These may be in response to a recently published article or a short free-standing piece expressing an opinion.

\section{Submitting Manuscripts}

\section{Cover letter}

Manuscripts should be submitted with a letter stating
(1) that the contents have not been published elsewhere; (2) that the paper is not being submitted elsewhere (or provide information on previous publication); and (3) that the authors agree to transfer copyright to the $C M J$ if the article is selected for publication. The letter should acknowledge any potential conflict of interest (see Ethical Responsibilities below) and call the editors' attention to any possible overlap with prior publications. The name, full mailing address, and telephone number of the author responsible for correspondence about the paper should also be included. E-mail addresses are mandatory.

Submit an original copy and 3 copies (photocopies are acceptable) of all parts of the manuscript, 3 original glossy prints of all figures, and 2 copies of the cover letter. All submissions must be accompanied by an electronic copy of the manuscript and illustrations. The manuscript should be mailed, with adequate protection for figures, to the Editors, Ceylon Medical Journal, 6 Wijerama Mawatha, Colombo 7, SRI LANKA.

Articles can also be submitted on-line (http:// www.sljol.info/index.php/CMJ/index).

\section{Ethical Responsibilities}

\section{Criteria for authorship}

Only persons who contributed to the intellectual content of the paper should be listed as authors. Authors should meet all of the following criteria, and be able to take public responsibility for the content of the paper.

1. Conceived and planned the work that led to the paper, or interpreted the evidence it presents, or both.

2. Wrote the paper or reviewed successive versions, and took part in revising them.

3. Approved the final version.

4. Each author should have contributed sufficiently to the work to take public responsibility for the content.

Collecting and assembling data reported in a paper and performing routine investigations are not, by themselves, criteria for authorship.

\section{Conflict of interest}

Financial support for the work, including equipment and drugs, should be listed on the title page. Authors should describe in the cover letter any financial interests, direct or indirect, that might affect the conduct or reporting of the work they have submitted. If uncertain as to what might be considered a potential conflict of interest, on the side of full disclosure. Information about potential conflict of interest may be made available to referees and will be published with the manuscript, at the discretion of the editors.

\section{Previous publication}

In the cover letter give full details on any possible previous publication of any content of the paper. eg.

1. Reworked data already reported.

2. Patients in a study already described and published.

3. Content already published or to be published in another format. 
Previous publication of some content of a paper does not necessarily preclude it being published in the $C M J$, but the editors need this information when deciding how to make efficient use of space in the journal, and regard failure of a full disclosure by authors of possible prior publication as a breach of scientific ethics.

\section{Informed consent}

The authors must ensure that informed consent has been obtained. Authors should state in the methods section, when appropriate, the ethical guidelines followed.

If patients are recognisable in illustrations, signed consent by the patients (or guardians) must be submitted with the paper.

\section{Selection for publication}

All articles received will be acknowledged to the corresponding author. Each manuscript will be read by the editors to decide whether it should be further reviewed. Those selected for review will be sent anonymously to referees.

\section{Peer review}

Referees are asked to treat papers as confidential communications and not to share their content with anyone except colleagues they have asked to assist them in reviewing, or to use content for their own purposes. They are asked to declare any conflict of interest (such as personal ties to authors), and not to copy manuscripts.

\section{Editorial board}

All articles are submitted anonymously to the Editorial Board which meets once a month. Members of the board assess articles on the basis of importance of the research problem, scientific strength, clarity of presentation and appropriateness for readers of the $C M J$.

Editors reserve the right to modify style, shorten articles, make editorial corrections where necessary, and to determine priority and time of publication.

\section{Preparation of Manuscript}

The $C M J$ will consider all manuscripts prepared in accordance with the uniform requirements for manuscripts submitted to biomedical journals developed by the International Committee of Medical Journal Editors [1]. A summary of these and the requirements of the $C M J$ are given below.

\section{Manuscript typing}

All parts of manuscript, including tables and figure legends, must be typed with double-spacing. References must also be double spaced. Manuscripts should be typed in capital and lower case letters, on white paper, $216 \times$ $279 \mathrm{~mm}(8 \times 11 \mathrm{in})$, or A4 $(212 \times 297 \mathrm{~mm})$. Arrange components in the following order: title page, abstract, text, references, tables in numerical sequence, and figure legends. Begin each component on a separate page. Number all pages consecutively, starting with the title page.

\section{Title page}

The title page should contain the following:

1. Main title, subtitle (if any) and a maximum of 5 index words (or phrases).

2. Authors listed in the form and order in which they are to appear in the published article.
3. Institutional affiliation for each author, in a footnote on the title page of the article. The institutions listed should reflect the affiliations of the authors at the time of the study, not their present affiliations, if they differ.

4. Financial support information. Include the grant number, if any, and the granting agency. Other financial support, such as that for equipment and drugs, should also be listed.

5. Name, address, e-mail and telephone number of author responsible for correspondence.

6. The number of words in the manuscript, exclusive of the abstract, references, tables, figures, and figure legends.

\section{Abstract}

Abstracts for articles are limited to 250 words; those for Brief Reports, to 150 words. Authors of original research articles are asked to submit a structured abstract organised into the following categories (where relevant): Objective(s), Design, Setting, Patients, Intervention (if any), Measurements, Results, Conclusion(s).

Authors are asked to see papers in any recent issue of the British Medical Journal or Annals of Internal Medicine for guidance on structuring the abstract.

\section{Headings in text}

Use only three levels of headings in the text. Clearly indicate the levels of headings by using different typographic conventions (such as all capital letters or bold type) or by positioning (flush to margin, indented). Keep headings short (three or four words).

\section{Style}

The British Medical Journal, Lancet and Annals of Internal Medicine are recommended to authors as guides to style, clarity of presentation and conciseness.

\section{Name of drugs and instruments}

Generic names must be used for all drugs. Include the proprietary name only if it is needed for a specific purpose. Instruments may be referred to by proprietary name, giving the name and location of the manufacturer in the text in parentheses.

\section{References}

Number references in the order in which they are first cited in the text. Use arabic numerals within parentheses. Note that the CMJ requires the COMPLETE name of journal (and not its abbreviation), year, volume and first and last page numbers.

The reference list should not include unpublished material. Symposium papers may be cited from published proceedings; oral presentation of a paper at a meeting does not constitute publication. References to articles or books accepted for publication but not yet published must include the title of the journal (or name of the publisher) and the year of expected publication. Unpublished work (personal communication, papers in preparation) may be cited by inserting a reference within parentheses in the text; authors must submit a letter of permission from the cited persons to cite such communications. 
Sample references below are in the style required by the $C M J$.

Journals: List all authors when 4 or fewer; when 5 or more, list only the first 3 and add et al.

1. Standard article.

Bernstein H, Gold H. Sodium diphenylhydantoin in the treatment of recurrent arrhythmias. Journal of the American Medical Association 1965; 191: 695-9.

2. Corporate author.

The Royal Marsden Hospital Bone Marrow Transplantation Team. Failure of syngeneic bone marrow graft without preconditioning in posthepatitis marrow aplasia. Lancet 1977; 2: 242-4.

3. Special format.

Cahal DA. Methyldopa and haemolytic anaemia (Letter). Lancet 1975; 1: 201.

Books: List all authors or editors when 4 or fewer; when 5 or more, list only the first 3 and add et al.

1. Author.

Eisen HN. Immunology: An introduction to molecular and Cellular Principles of the Immune Response. 5th ed. New York: Harper and Row,1974.

2. Editors.

Dausset J. Colombani J, eds. Histocompatibility Testing 1972. Copenhagen: Munksgaard, 1973.

3. Chapter in a book.

Hellstrom I, Helstrom KE. Lymphocyte-mediated cytotoxic reactions and blocking serum factors in tumor-bearing individuals. In: Brent L, Holbrow J, eds. Progress in immunology II. v. 5. New York: American Elsevier, 1974: 147-57.

Other citations in Reference List:

1. In press (must have journal title).

Dienstage JL. Experimental infection in chimpanzees with hepatitis A virus. Journal of Infectious Diseases 1975. In press.

2. Magazine article.

Roueche B. Annals of medicine: the Santa Claus culture. The New Yorker 1971. Sep 4: 66-81.

In-text citations of unpublished material (to be placed within parentheses):

1. Personal communication.

(Strott CA, Nugent CA. Personal communication).

2. Unpublished papers.

(Lerner RA, Dixon FJ. The induction of acute glomerulonephritis in rats. In preparation). (Smith J.

New agents for cancer chemotherapy. Presented at the Third Annual Meeting of the American Cancer Society, June 13, 1983, New York). Tables

All tables must be typed double-spaced. Tables should be numbered with arabic numerals, in the order in which they are cited in the text. A table title should describe concisely the content of the table.

\section{Figures}

Figures should be professionally drawn or prepared using a computer and high-resolution printer. Lettering should be uniform in style. Free hand or typewritten lettering is not acceptable. Number the figures in the order in which they are cited in the text. Photomicrographs should have scale markers that indicate the degree of magnification. Submit three glossy prints of each figure. Indicate on a label the name of the first author of the paper, the figure number, and the top of the figure: then paste the label on the back of the figure. Do not mount figures on backing board.

Colour figures may be submitted and will be published if essential. Three colour prints should be submitted for each figure. Colour photographs are included only if publishing costs are borne by the author (Rs. 4,000/=). Authors may also be asked to contribute towards the cost of publishing black and white photographs (Rs. 1,000/=).

\section{Legends for figures}

Reduce the length of legends by using partial sentences. Explain all abbreviations and symbols on the figure, even if they are explained in the text. Stain and magnification should be given at the end of the legend for each part of the figure. If there is no scale marker on the figure, the original magnification used during the observation should be given, not that of the photographic print.

\section{Acknowledgements}

Acknowledge only persons who have contributed to the scientific content and provided financial or technical support. Authors must submit written permission from persons acknowledged for other than financial or technical support.

\section{Handling charge}

A nominal handling fee of Rs 1,000/= will be charged from authors at the time of submission of an article. This fee is not refundable. Please write your cheque in favour of 'The Ceylon Medical Journal Account 003010146873 (Hatton National Bank)'. The handling fee for authors from overseas is as follows.

SAARC countries US D 20

UK and Europe US D 30

All other countries US D 35

\section{Editorial correspondence}

Address all editorial correspondence to the Editor, The Ceylon Medical Journal, 6 Wijerama Mawatha, Colombo 7, Sri Lanka.

\section{References}

1. International Committee of Medical Journal Editors. Uniform requirements for manuscripts submitted to biomedical journals. New England Journal of Medicine 1991; 324: 424-8.

2. WHO Research Ethics Review Committee. The process of obtaining informed consent. http:// www.who.int/rpc/research_ethics/informed_ consent/en/

3. Young D. Implementation of SI units for clinical laboratory data: style specifications and conversion tables. Annals of Internal Medicine 1987; 106: 114-29. 